\title{
Synergies and compromises between charge and energy transfers in three-component organic solar cells
}

Received 00th January 20xx Accepted 00th January 20xx

DOI: $10.1039 / x 0 x \times 00000 x$

\author{
Camillo Sartorio, ${ }^{a}$ Giuliana Giuliano, ${ }^{a}$ Michelangelo Scopelliti, ${ }^{a}$ Valeria Vetri, ${ }^{a}$ Maurizio Leone, ${ }^{a}$ \\ Bruno Pignataro ${ }^{a, *}$
}

\begin{abstract}
In this paper, we developed different three-component organic heterojunction structures supported by PET/ITO substrates with the aim to study the possible synergies and/or compromises between charge transfer (CT) and energy transfer (ET) processes in organic solar cells (OSCS). As components we employed the poly(3-hexylthiophene-2,5-diyl) (P3HT; donor), the $[6,6]$-phenyl- $\mathrm{C}_{61}$-butyric acid methyl ester (PCBM; acceptor) and the poly(9,9-dioctylfluorene-alt-benzothiadiazole) (F8BT) that is known to give good ET to P3HT. At first, we observed that in a planar heterojunction(PHJ) solar cell, F8BT has to be properly located in between $\mathrm{P} 3 \mathrm{HT}$ and PCBM to get a cascade energy levels configuration allowing for a better CT and power conversion efficiency. Then, we observed that by performing a P3HT:F8BT blend, the energy transfer process can be improved in the $\mathrm{P} 3 \mathrm{HT}: \mathrm{F} 8 \mathrm{BT} / \mathrm{PCBM}$ active layer. This may allow for decreasing the thickness of the active layer by maintaining similar PCE that is very interesting for the development of transparent OSCs. However, the P3HT:F8BT blend limits the P3HTPCBM CT with respect to a P3HT/F8BT/PCBM PHJ showing that a compromise between CT and ET is needed to get higher $\mathrm{PCE}$ or higher transparency. By the above approach, in this paper we developed highly transparent heterojunction structures able to give in solar cell devices PCE comparable to those observed by the colorful reference P3HT/PCBM PHJ solar cells on PET/ITO substrates.
\end{abstract}

\section{Introduction}

Organic Solar Cells (OSCs) continues to be of great interest because of their flexibility, lightness, and potential for low-cost and simplicity of the manufacturing processes. Recently, promising power conversion efficiency (PCE) values have been obtained, thanks to the development of new materials and the design of new architectures with the highest PCE reached over $17 \% .^{1-3}$ In the last few years, flexible and semitransparent OSCs have aroused by far the most interest for their promising applications in wearable energy resources, building-integrated photovoltaics as windows or skylights where it is difficult to install conventional solar cells, or in new applications such as multi-junction solar photovoltaics. ${ }^{4,5}$ In addition, the employment of plastic substrates allows for the development of flexible, portable and biocompatible devices, also implementable on curved surfaces and on tissues. However, when OSCs are realized on a plastic substrate instead of glass, PCE values further decrease due to the higher surface resistivity of the electrode on the substrate and the lower light transparency of the plastic. ${ }^{6-9}$

Thanks to the much higher performance obtained, most of the literature was dedicated to OSCs with bulk heterojunction (BHJ)

\footnotetext{
a. Dipartimento di Fisica e Chimica, Università degli Studi di Palermo, V.le delle Scienze Ed. 17, 90128, Palermo, Italy. *Corresponding author: e-mail bruno.pignataro@unipa.it

$\dagger$ Footnotes relating to the title and/or authors should appear here.

Electronic Supplementary Information (ESI) available: [details of any supplementary information available should be included here]. See DOI: 10.1039/x0xx00000x
}

architectures, while contributions for the development of planar heterojunction (PHJ) solar cells are scarce. From the process point of view, realizing a PHJ device would allow easier scalability to large area manufacturing since of a better morphological and structural control than $\mathrm{BHJ}$, which need the appropriate organization of donor and acceptor materials during the spin-coating or the post-production process. ${ }^{10-17}$

Moreover, in the PHJs the free charge carriers can benefit from a continuous pathway to the electrodes, contrary to what happens in the BHJs where the presence of a large number of "insulated" domains does not ensure the charge transport. In addition, the PHJ has the further advantage that the donor and acceptor phase contact the anode and the cathode selectively, thus favoring the correct charge extraction. Indeed, the fill factor (FF) of PHJs is usually larger compared to that of BHJs due to the spatial separation of different charge carriers at the donor/acceptor interface, resulting in a high charge carrier concentration gradient that promotes the charge transport. Nevertheless, in spite of these advantages, PHJs exhibit low PCEs than BHJs due to the restricted donor/acceptor interface, resulting in a limited exciton dissociation. ${ }^{10,16,18-27}$ This suggests that the donor/acceptor interface and therefore the exciton dissociation play a predominant role for the PCE. To set the following discussion into context, it is helpful to first introduce a simplified expression for the photocurrent efficiency $\left(\eta_{p h}\right)$ :

$$
\eta_{\text {ph }} \propto \eta_{\text {abs }} \times \eta_{\text {diss }} \times \eta_{\text {out }}
$$

Indeed, by considering that the number of created charges collected at the electrodes can be expressed as a function of the fraction of photons absorbed $\left(\eta_{a b s}\right)$, the fraction of the 
dissociated excitons $\left(\eta_{\text {diss }}\right)$ and the fraction of the free charges that reach the electrodes $\left(\eta_{\text {out }}\right)$, it is clear that the employment of the PHJs, instead of the BHJs, ensures a great advantage in relation to $\eta_{\text {out, }}$ no significant difference in $\eta_{\text {abs }}$, but a considerable decrease of $\eta_{\text {diss. }}$. This is conventionally counteracted through the reduction of the bilayer thickness in order to increase the percentage of generated excitons near the donor/acceptor interface. However, while on one hand this approach improves $\eta_{\text {out }}$, on the other it leads to the reduction of $\eta_{a b s}$. This point becomes even more relevant for future application in transparent OSCs, where the transparency of the active layer is usually increased by simply decreasing the thickness of the active thin film.

However, this will lead to a lower PCE because less light is absorbed by a thinner layer, so a trade-off between photocurrent generation and device transmittance is needed. In this regard, the greater challenge is to improve efficiencies by developing strategies to increase light harvesting without increasing the thickness of the heterojunction. ${ }^{28,29}$

On this respect, the device engineering has played a key role for example with the development of tandem devices, consisting of multiple layers of different materials which usually show complementary absorption, ${ }^{30-32}$ but the tandem devices fabrication requires complicated and expensive manufacturing. ${ }^{32-37}$ A promising alternative for combining the improved photoconversion of tandem devices with the simplicity of the typical manufacturing processes of OSCs, is the realization of three-component heterojunctions. In this regard, Honda et al. reported an enhancement of the light-harvesting efficiency in P3HT:PCBM BHJ solar cells by employing nearinfrared phthalocyanine molecules as the third component of the active layer. ${ }^{38}$ Similar results have been obtained by Huang et al. by using squaraine dye in heterojunction polymer solar cells with P3HT. They showed that the use of squaraine not only leads to increased light absorption, but also ensures an improved exciton migration over long distances by Förster resonance energy transfer (FRET). ${ }^{39}$ Apart from extending the absorption of the active layer, the addition of a third component could allow an improvement of the heterojunction morphology, for example, by acting as a template for a better supramolecular organization. ${ }^{31,40}$ For example, in a previous work we showed how the incorporation of small quantities of copolymers into $\mathrm{P} 3 \mathrm{HT}$ :PCBM heterojunctions on plastic results in a good control of the phase separation process along with an enhanced PCE. ${ }^{41} \mathrm{Kim}$ et al. showed how the performance of a P3HT:PCBM BHJ device is improved by morphological changes induced by the presence of F8BT, which also improves the miscibility between the donor and acceptor materials. ${ }^{42}$ In another studies, the third component generates a cascade structure of donor and acceptor energy levels, resulting in an improved exciton dissociation. ${ }^{43-48}$

In this work, we pursue the goal of improving the performance of a P3HT-PCBM plastic solar cell, by using F8BT as a third component, with the awareness of necessarily having to

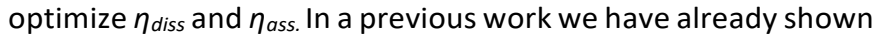
how it is possible to significantly improve $\eta_{\text {diss }}$ by using gold nanoparticles able to increase and localize the exciton generation at the donor/acceptor interface in a PHJ. ${ }^{17}$ Here, we show how this challenge is also achievable without using expensive materials but by simply incorporating a polymer able to induce an energy transfer (ET) to the electron donor material and, at the same time, to generate a cascade structure. In particular, we demonstrate that it is not sufficient to disperse the third component in the heterojunction, but it is necessary to properly engineer a multilayered structure in order to optimize its effect.

In addition, we study the effect of the position of the third component within the heterojunction in order to understand and exploit a possible its double role: a "bridge" in an energy level cascade structure; an "exciton injector" by the remarkable FRET to the P3HT. Finally, we show how it is possible to employ a simple and low-cost approach consisting of three sequential solution depositions, in spite of most of literature employing complicated and time-consuming thermal evaporation processes to develop multilayered functional structures.

\section{Experimental}

\section{Materials and methods}

Langmuir - Schaefer. PHJs have been prepared by using a layerby-layer approach by means of the Langmuir-Schaefer technique (LS). In particular, LS films have been realized by using a KSV Minitrough apparatus with ultrapure Millipore filtered water (resistivity greater than $18.2 \mathrm{M} \Omega \mathrm{cm}$ ) used as subphase at a temperature of $25^{\circ} \mathrm{C}$. P3HT (regioregular 91- 94\%, electronic grade, average Mn 50 000- 70 000, Rieke Metals, Inc.) layers have been obtained by spreading over the aqueous surface 400 $\mu \mathrm{L}$ of a $0.1 \mathrm{mg} \mathrm{mL}^{-1}$ solution in chloroform. After solvent evaporation (about $10 \mathrm{~min}$ ) the floating films were linearly compressed by means of two mobile barriers at a rate of 5 $\mathrm{mm} / \mathrm{min}$. The ultrathin films were transferred on poly(ethylene terephthalate coated by indium tin oxide (PET/ITO) substrates (Aldrich, surface resistivity $60 \Omega / \mathrm{sq}$ ) square substrates (about 1 $\mathrm{cm} 2$ ), at a $20 \mathrm{mN} \mathrm{m}^{-1}$ surface pressure. In the same way, to obtain a PHJs with the desired structure, PCBM (MW 911, > 99.5 purity, Ossila) and F8BT (MW 21500 with polydispersity 2.9, American Dye Source) have been deposited by starting from solution of $0.2 \mathrm{mg} \mathrm{mL}^{-1}$ in chloroform and $0.1 \mathrm{mg} \mathrm{mL}^{-1}$ in chlorobenzene, respectively.

Spin Coating. Devices based on the PET/ITO/HTL (hole transport layer)/PHJ/Al structure were fabricated by spin coating on the $\mathrm{PET} / \mathrm{ITO}$ substrates. The substrates were cleaned sequentially by sonication in methanol, acetone and isopropanol for $10 \mathrm{~min}$ each, followed by cleaning in a UV-ozone cleaner (Procleaner Plus, Bioforce) for $20 \mathrm{~min}$. The hole-transport material poly(ethylenedioxythiophene):poly(styrenesulfonate)(PEDOT:P SS, Aldrich, 1.3 wt \% dispersion in $\mathrm{H}_{2} \mathrm{O}$, conductive grade) was spin-coated onto the substrates at $4000 \mathrm{rpm}$ and dried at 100 ${ }^{\circ} \mathrm{C}$ for $10 \mathrm{~min}$ on a hot plate. After this, the PET/ITO/PEDOT:PSS systems were transferred in gloveboxe (MBraun, Germany) filled with $\mathrm{N}_{2}\left(<0.1 \mathrm{ppm}\right.$ of $\mathrm{O}_{2}$ and $\left.\mathrm{H}_{2} \mathrm{O}\right)$, where $\mathrm{P} 3 \mathrm{HT}(20 \mathrm{mg} \mathrm{mL}$ 1 in chlorobenzene), F8BT ( $0.5 \mathrm{mg} \mathrm{mL}^{-1}$ in dichloromethane) and 
PCBM (5 mg mL-1 in a 1:0.5 mixture of dichloromethane: acetone) solutions have been sequentially deposited at 1500 rpm on PET/ITO/PEDOT:PSS . In order to allow drying, at least 15 minutes shall lapse between the different deposition processes. Always in gloveboxe, $100 \mathrm{~nm}$ Al were thermally evaporated as cathode to complete the devices. The thickness of P3HT and PCBM films was maintained at about 50 and $30 \mathrm{~nm}$, respectively by using so-called "orthogonal solvents" (solvents that behave as good solvents for the layer to be deposited but that do not affect the morphology of the polymer below). ${ }^{10,17}$

Optical Characterization. UV-Vis absorption and fluorescence spectra were recorded on thin films deposited on PET/ITO substrates, using a Specord S 600 (Analytik Jena, Jena, Germany) and Fluoromax-4 (HORIBA Jobin Yvon, Edison, USA) spectrofluorometer equipped with a $150 \mathrm{~W}$ xenon arc lamp as the excitation source, respectively.

Fluorescence Lifetime Imaging Measurements. Fluorescence lifetime measurements were performed on uniform samples of molecular layers drop-casted sequentially (one on top of the other) over a coverglass using a fluorescence lifetime imaging (FLIM) apparatus. $30 \mu \mathrm{m} \times 30 \mu \mathrm{m}$ areas were investigated in order to obtain homogenous images. FLIM data were acquired in the time domain by means a Leica TCS SP5 inverted microscope (Leica Microsystems) equipped with picoHarp 300 stand-alone TCSPC module (Picoquant). Thus $256 \times 256$ images were acquired at $400 \mathrm{MHz}$ scan speed using the supercontinuum white laser source (Leica Microsystems) as 80 $\mathrm{MHz}$ pulsed source. Excitation wavelength for all images was set at $475 \mathrm{~nm}$, and the fluorescence signal was acquired in the 600$730 \mathrm{~nm}$ spectral region. Data were analyzed using the phasor approach, SimFCS software (Laboratory for Fluorescence Dynamics, University of California, Irvine, CA) was used for data analysis. This method allows a straightforward interpretation of data without fitting procedure giving a global view of the fluorescence decay in each pixel of an image. ${ }^{49,50}$ In the phasor analysis single exponential lifetimes lies on the so-called "universal circle" defined as the semicircle going from point $(0,0)$ to point $(1,0)$, with radius $1 / 2$. Point $(1,0)$ corresponds to $\tau=0$, and point $(0,0)$ to $\tau=\infty$. FLIM calibration of the system was obtained by considering $\mathrm{P} 3 \mathrm{HT}$ samples lifetimes as characterized by single exponential 0.57 ns lifetime. ${ }^{51,52}$ This procedure allows a simple comparison between all samples avoiding artefacts or noise due to reflections and change in refraction index in the different samples. Results are fully in agreement with what previously reported. ${ }^{17}$ Under the selected spatiotemporal resolution all the samples are characterized by homogenous average lifetime.

X-Rays Photoelectron Spectroscopy. XPS measurements (depth profiles) were carried out by means of a ULVAC-PHI PHI 5000 VersaProbe II, using a monochromatic Al source (AI K $\mathrm{K}_{\alpha}=1486.6$ $\mathrm{eV}$ ) on a $200 \mu \mathrm{m}$ diameter spot, $45^{\circ}$ takeoff angle, with dual beam charge neutralization system to compensate the chargeup effect. Surfaces were sputtered with a $\mathrm{Ar}^{+}$ion gun ( $3 \mathrm{~mm} \times 3$ $\mathrm{mm}$ rastering area, $1 \mathrm{kV}$ acceleration; time step $0.5 \mathrm{~min} \equiv 30 \mathrm{~s}$ ). The sputtering rate was calibrated by using a thermally oxidized $\mathrm{SiO}_{2} 80 \mathrm{~nm}$ in thickness, that, in our conditions, has been fully sputtered with a rate of $1.37 \pm 0.02 \mathrm{~nm} / \mathrm{min}$. In order to obtain the discontinuity points within the profile curves, a piecewise function fitting was used means of NumPy and SciPy.

Electrical Measurements. Current - voltage curves were acquired by using a Keithley 2400 source meter and a halogen lamp as illumination source, having an irradiance power of 100 $\mathrm{mW} \mathrm{cm}^{-2}$. All measurements were performed in a glovebox system (MBraun, Germany) filled with $\mathrm{N}_{2}\left(<0.1 \mathrm{ppm}\right.$ of $\mathrm{O}_{2}$ and $\mathrm{H}_{2} \mathrm{O}$ ).

\section{Results and Discussion}

\section{Transfer Processes at the Interfaces}

In order to investigate charge or ET processes that take place at the donor-acceptor interface, bi-component and threecomponent PHJs (tc-PHJs) with a different layer sequence have been realized and studied by fluorescence experiments. In particular, to realize PHJ films we used the Langmuir-Schaefer technique as it provides a high control of thickness, morphology and structure of each deposited layer and, more importantly, ensures an accurate organization of the interface where the transfer processes occur. ${ }^{43} \mathrm{In}$ addition, this technique makes it possible to employ very low quantities of materials that can be soluble even in different solvents, since each layer is deposited from the air-water interface, independently. In this regard, in a previous work we showed how this approach allows realizing thin PHJ films of P3HT, PCBM and F8BT where the single layer has a thickness of about 4-6 nm. ${ }^{53}$

It must be underlined that a quantitative description of the charge transfer (CT) in a three-component system becomes even more complex when two fluorophores and two processes with opposite effects on fluorescence are involved. Indeed, the ET should induce a fluorescence quenching of F8BT (energy donor) and an increase in fluorescence of P3HT (energy acceptor), but the simultaneous $\mathrm{CT}$ from $\mathrm{P} 3 \mathrm{HT}$ (electron donor) to F8BT (electron acceptor) would lead to the opposite effect. ${ }^{17,53,54}$ However, although the LUMO $_{\text {P3HT }}-$ LUMO $_{\mathrm{FBBT}}$ offsets is large enough for the exciton dissociation, the charge separation in P3HT/F8BT systems is negligible with respect to the ET (Figures 1a and 1c). ${ }^{54}$

In fact, the separation distance between the benzothiadiazole acceptor units in F8BT and the thiophene donor units in P3HT is too long for an efficient exciton dissociation but may be adequate for ET, since the latter is a long range process. ${ }^{54}$ In addition, the exciton dissociation is limited at the P3HT/F8BT interface with respect to the $\mathrm{P} 3 \mathrm{HT} / \mathrm{PCBM}$ interface. Indeed, preliminary FLIM measurements, carried out on bi-component drop casted systems (P3HT/PCBM, P3HT/F8BT, and F8BT/PCBM), showed that the fluorescence lifetime obtained for P3HT/PCBM resulted shorter than that of P3HT/F8BT. On this basis, it might seem reasonable to assume that more advantageous three-component planar configuration should not implement a layer of F8BT at the P3HT/PCBM interface (Figure 1d), where it would hinder the CT. F8BT would better be only in contact with $\mathrm{P} 3 \mathrm{HT}$ (Figure 1e) to act almost exclusively as an exciton "injector", without affecting the CT from P3HT to PCBM. 


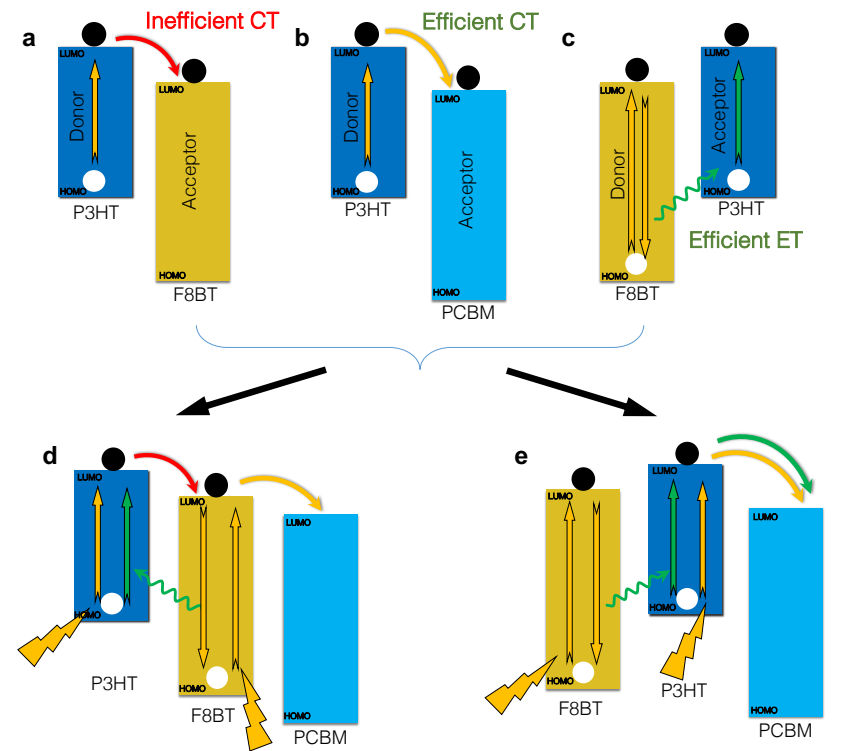

Fig. 1 Schematic representation of different interface structures in two and threecomponent PHJ systems: a) a P3HT/F8BT interface gives an inefficient $\mathrm{CT}$; b) efficient $\mathrm{CT}$ in $\mathrm{P} 3 \mathrm{HT} / \mathrm{PCBM}$; c) efficient $\mathrm{ET}$ in $\mathrm{F} 8 \mathrm{BT} / \mathrm{P} 3 \mathrm{HT}$; d-e) the three-component $\mathrm{P} 3 \mathrm{HT} / \mathrm{F} 8 \mathrm{BT} / \mathrm{PCBM}$ and F8BT/P3HT/PCBM systems may both couple ET and CT, the first through a cascade energy levels structure. The green and yellow arrows represent the processes resulting from $\mathrm{ET}$ and $\mathrm{CT}$, respectively.

In this way, the exciton generation into the P3HT layer would be improved along with the charge collection to PCBM. Figure 2 shows the fluorescence spectra recorded on different planar layered systems obtained by LS on PET/ITO. As to the $\mathrm{F} 8 \mathrm{BT} / \mathrm{P} 3 \mathrm{HT} / \mathrm{PCBM}$ sequence, the F8BT film is deposited as the first layer of a tc- $\mathrm{PHJ}_{1}$ with no contact between F8BT and PCBM. The observed fluorescence of the pristine $\mathrm{P} 3 \mathrm{HT}$ film (black line) is very weak compared to the pristine F8BT (purple line - scaled by a factor of 10). Indeed, in order to obtain significant signals, it is necessary to realize PHJs with an amount of P3HT 5 times higher than F8BT.

In this PHJ (red line) the fluorescence of F8BT (535 nm) undergoes a notable quenching (greater than 90\%) due to the ET to P3HT, which simultaneously shows an intensity increase $(645 \mathrm{~nm})$. The deposition of the electron acceptor (PCBM) on

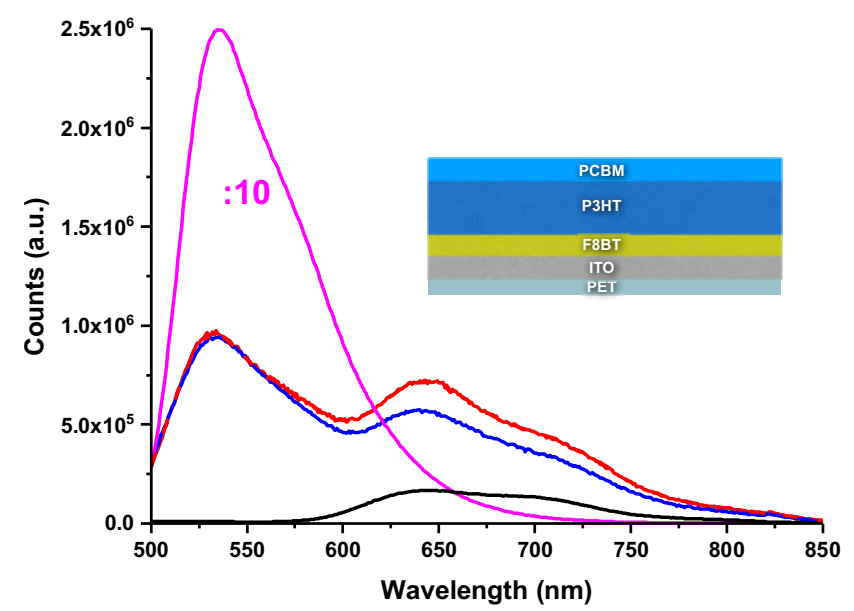

Fig. 2 Fluorescence spectra of different planar layered systems obtained by $L S$ on PET/ITO: F8BT (magenta), P3HT (dark), P3HT/F8BT (red), F8BT/P3HT/PCBM (blue line). The scheme on the top right shows the complete sequence of this last system. the top of the $\mathrm{PHJ}$ induces a weak fluorescence quenching (about 10\%) of $\mathrm{P} 3 \mathrm{HT}$, originated from the CT (blue line). $53,55,56$ In addition, the fluorescence of F8BT remains unchanged, indicating that no further ET effectively occurs after the introduction of PCBM on the surface of $\mathrm{P} 3 \mathrm{HT}$. Although the use of the F8BT as interlayer between P3HT and PCBM is discouraged by the inefficient P3HT-F8BT CT, we performed the fluorescence measurements also on this system (tc- $\mathrm{PHJ}_{2}$ ), to better investigate the transfer process at the different interfaces (Figure 3). Obviously, the fluorescence spectrum of a bi-component P3HT/F8BT heterojunction (red line) is identical to that reported in Figure 2. Once PCBM is deposited on top resulting in a $\mathrm{P} 3 \mathrm{HT} / \mathrm{F} 8 \mathrm{BT} / \mathrm{PCBM} \mathrm{PHJ}$, it shows a remarkable fluorescence quenching (blue line) that is a very different behavior from that of the P3HT/PCBM interface of Figure 2.

This highlights the critical role of the F8BT layer, which would act at the same time as a $\mathrm{P} 3 \mathrm{HT}$ energy donor and a PCBM electron donor in agreement with the respective LUMO level positions (Figure 1). Also, in this system there is no fluorescence emission from $\mathrm{P} 3 \mathrm{HT}(645 \mathrm{~nm})$. By considering that there is no direct contact between $\mathrm{P} 3 \mathrm{HT}$ and $\mathrm{PCBM}$, this result strongly implies that the CT involves the F8BT layer.

Note that more likely the complete quenching of $\mathrm{P} 3 \mathrm{HT}$ cannot be attributed to a limited ET process due to the dissociation of F8BT excitons by PCBM.

Indeed, as discussed above, the rapid ET ( $<1 \mathrm{ps)}$ ) suggests that most of F8BT excitons are efficiently transferred to $\mathrm{P} 3 \mathrm{HT}$. Thus, the presence of F8BT at the donor/acceptor interface would ensure a more efficient charge separation and this can be more likely ascribed to the presence of a cascaded HOMO and LUMO energy levels, which would energetically favour the CT at the interfaces owing to the bridging effect.44,57-59 In particular, PCBM can provide a driving force to transfer the electrons on the LUMO of F8BT to the LUMO of PCBM, thus favouring further CT from P3HT to F8BT (Figure 4) and therefore again to PCBM. ${ }^{58}$ In Figure 5 the analysis of FLIM measurements on different drop casted samples (P3HT, P3HT-PCBM, P3HT-F8BT, P3HT-F8BT$\mathrm{PCBM})$ are reported in a phasor plot.

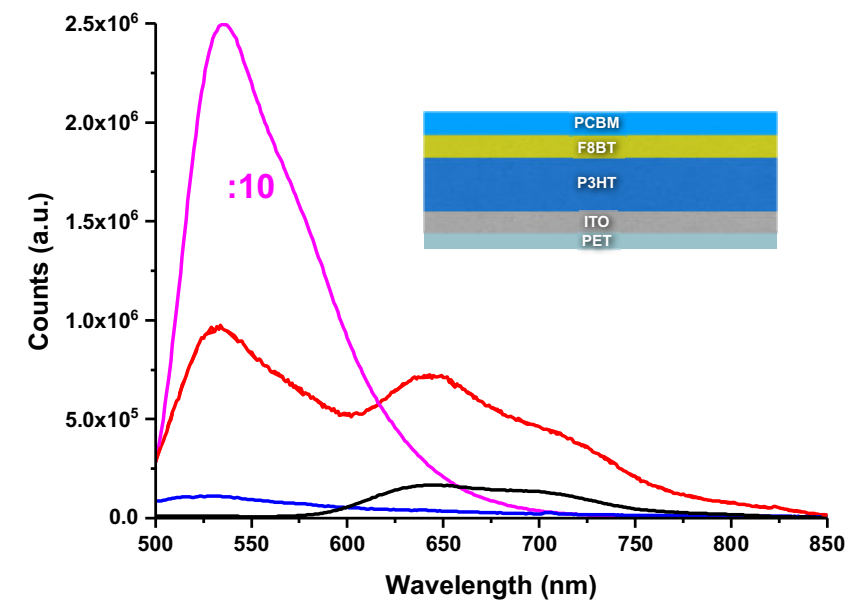

Fig. 3 Fluorescence spectra of different planar layered systems on PET/ITO: F8BT (magenta), P3HT (dark), P3HT/F8BT (red), P3HT/F8BT/PCBM (blue line). The scheme on the top right shows the complete layers sequence of this last system. 
Cascaded energy levels
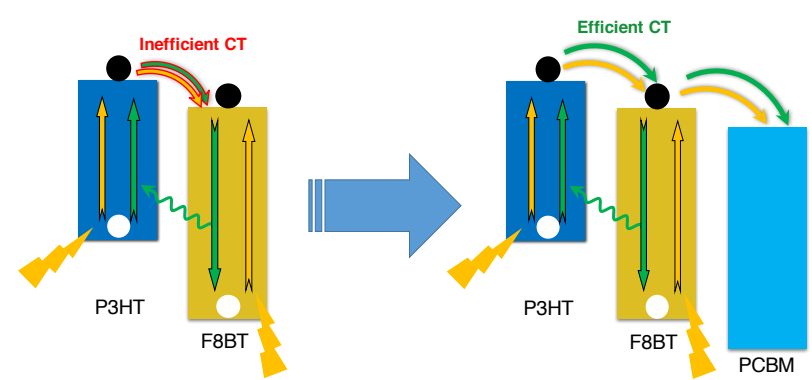

Fig. 4 Schematic representation of the transition in CT efficiency from the P3HT/F8BT interface to the $\mathrm{P} 3 \mathrm{HT} / \mathrm{F} 8 \mathrm{BT} / \mathrm{PCBM}$ cascade energy levels structure. The green and yellow arrows represent the processes resulting from $\mathrm{ET}$ and $\mathrm{CT}$, respectively.

This allowed a fast and quantitative visualization of the fluorescence lifetime distributions of $30 \mu \mathrm{m} \times 30 \mu \mathrm{m}$ areas imaged under excitation at $470 \mathrm{~nm}$. Fluorescence lifetimes are mapped to a point in the phasor plot corresponding to the measured fluorescence lifetime, observed clouds correspond to measured lifetime distributions.

This analysis, successfully applied on multiple systems allows overcoming fit procedures and provides a global view of the fluorescence decays without imposing a model.17,49,50,59,60 Longer lifetimes are located near the origin ( 0 on the $x$ axis), while shorter lifetimes are shifted on the circular line toward the bottom right intersection with the $x$ axis (1 on the $x$ axis). As can be seen the measured lifetime distribution of each sample lies on the universal circle thus indicating that in the present measurement conditions fluorescence decays are described in average by single exponentials.

In line with our previous results on analogous samples, the lifetime distribution of the P3HT/PCBM sample is significantly reduced with respect to that of the pristine $\mathrm{P} 3 \mathrm{HT}$ (assumed 0.57 ns for calibration). This can be possibly attributed to a photoinduced charge separation at the P3HT/PCBM interface. ${ }^{17,55,62,63}$ Interestingly, the presence of F8BT at the donor-acceptor interface seems to induce a further reduction of the excited state lifetime, suggesting an improved P3HTPCBM CT. In the present conditions (i.e. $\lambda_{\text {exc }}=470 \mathrm{~nm}$ ) the fluorescence lifetime results below the experimental time resolution limit.

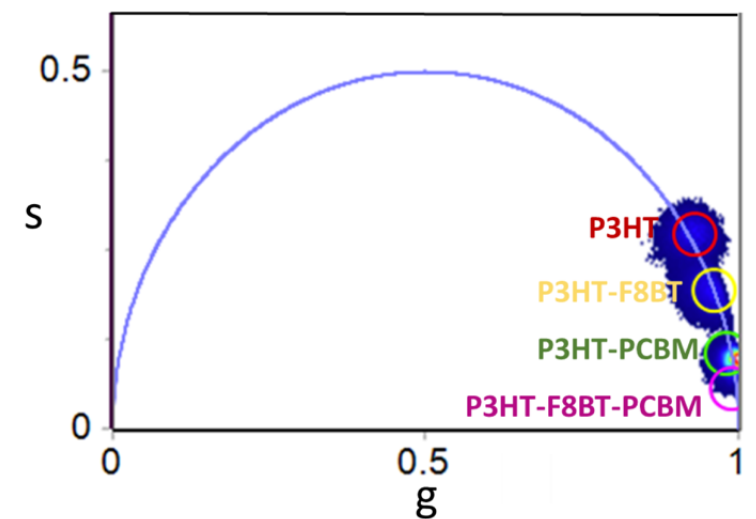

Fig. 5 Phasor plot showing the lifetime distribution of three different drop casted samples. The average lifetime is selected by a colored cursor: P3HT (red cursor); P3HTF8BT (yellow); P3HT-PCBM (green); P3HT-F8BT-PCBM (magenta). $\lambda$ exc $=470 \mathrm{~nm}$ Detection range $600-730 \mathrm{~nm}$
As mentioned above, it should be noted that the measured lifetime distribution of the P3HT/F8BT sample is reduced with respect to that of $\mathrm{P} 3 \mathrm{HT}$, but it is larger than $\mathrm{P} 3 \mathrm{HT} / \mathrm{PCBM}(\approx 0.3$ ns) being centered at about $0.4 \mathrm{~ns}$. This is in agreement with the formation of a cascade effect by the proper organization of these three materials, as discussed above with the steady-state emission spectra. These results clearly confirm that in the cases where both CT and ET processes occur, the third component needs to be located at the donor/acceptor interface to obtain an efficient CT thanks to the energy levels alignment. ${ }^{57}$

In light of this, it is desirable to realize PHJ devices to fully exploit the advantages of the ternary cascade structure, rather than realizing $\mathrm{BHJ}$ where the interface control is not guaranteed. However, further investigations revealed that the mixing of P3HT and F8BT ensures a significant ET enhancement by the larger interface of the donor/acceptor blend compared to that of the planar configuration. In particular, Figure 6 shows the fluorescence spectra of PHJs consisting of the P3HT:F8BT blend (red line) and the P3HT:F8BT/PCBM system (blue line). In this last case, the ET is so efficient that the spectra do not show any residual F8BT emission at $535 \mathrm{~nm}$. It is interesting to note that the $\mathrm{P} 3 \mathrm{HT}$ emission band observed for only one layer of the P3HT:F8BT blend is about 14 times more intense than that of 5 layers of the pristine $\mathrm{P} 3 \mathrm{HT}$. In other words, to obtain the same fluorescence intensity induced by the F8BT-P3HT ET, P3HT alone would need to be employed in an amount of about 70 times higher. This result may be useful in transparent solar cells where, as mentioned above, it is customary to decrease the thickness of heterojunction in order to improve the transparency of active layer.

\section{Tc-PHJ 2 -like structure by Spin-coating}

On the basis of the above results, we fabricated two kinds of photovoltaic devices, respectively with tc- $\mathrm{PHJ}_{2}$ and P3HT:F8BT/PCBM as active layers by employing a sequential spin-coating procedure of the different materials from solutions with orthogonal solvents. This approach has already been successfully applied to realize traditional bi-component PHJs but, to the best of our knowledge, this is again the first time that it is applied to realize tc-PHJ-like structures. ${ }^{10,17}$

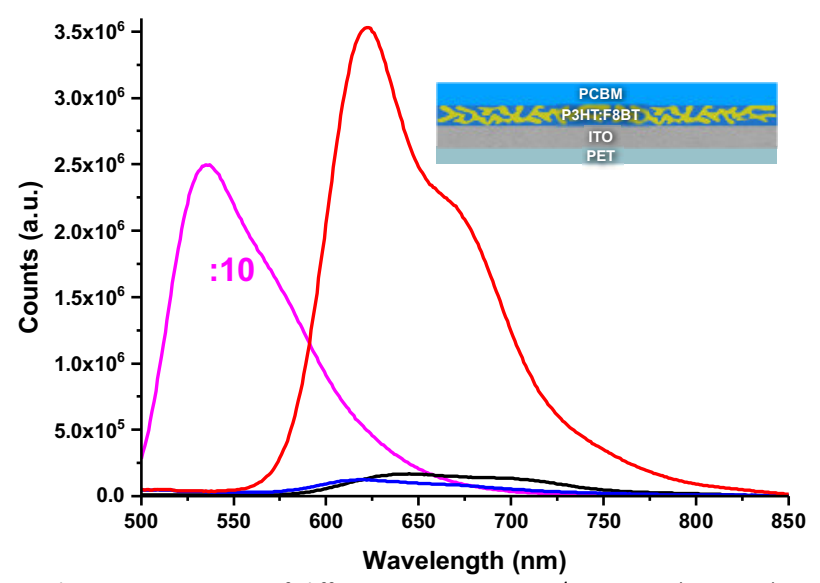

Fig. 6 Fluorescence spectra of different systems on PET/ITO: F8BT (magenta), P3HT (dark), P3HT:F8BT blend (red), P3HT:F8BT/PCBM (blue line). The scheme on the top right shows the complete layers sequence of this last system 
The devices have been developed by transferring a P3HT layer ( $20 \mathrm{mg} / \mathrm{mL}$ ) over a PET/ITO substrate and by depositing on top, in sequence, layers of $\mathrm{F} 8 \mathrm{BT}, \mathrm{PCBM}$ and $\mathrm{Al}$ as the top electrode (PET/ITO/P3HT/F8BT/PCBM/AI). XPS measurements confirmed the goodness of the chemical state of the different layers. Moreover, XPS depth profiling has been carried on the devices layers by following the $C 1 s, O 1 s, S 2 p$ and $\ln 3 d_{5 / 2}$ species (Figure 7). Although the spin-coating approach should not guarantee well-defined interfaces between each layer, our analysis allowed showing that no significant intermixing occurred between the different layers, with the P3HT and F8BT layers being of about $25 \mathrm{~nm}$ and $6 \mathrm{~nm}$ in thickness, respectively. In particular, the S2p signal in the F8BT/P3HT junctions shows a rising curve with the sputtering time reaching a plateau after about $6 \mathrm{~nm}$. This is consistent with a clearing of the whole F8BT layer in the first sputtered $6 \mathrm{~nm}$ by reaching the $\mathrm{P} 3 \mathrm{HT}$ layer with the plateau which extends for about $25 \mathrm{~nm}$. This picture has been corroborated by an independent measurement of a P3HT layer, without F8BT on top, showing a S2p constant value for a similar $25 \mathrm{~nm}$ thickness. Note that the P3HT layer thickness is maintained of this order for all the fabricated devices as an indication of the real orthogonality of the used solvents, thus revealing the effectiveness of our approach. Table 1 summarizes the photovoltaic parameters of different threecomponent devices compared to the reference planar device with a P3HT/PCBM active layer without F8BT ( $\mathrm{PHJ}$ rif). According to the literature values, the reference device exhibits an opencircuit voltage $\left(\mathrm{V}_{\mathrm{oc}}\right)$ of $0.48 \mathrm{~V}$, short-circuit current density $\left(\mathrm{J}_{\mathrm{sc}}\right)$ of $0.82 \mathrm{~mA} \mathrm{~cm}-2$, fill factor (FF) of 0.38 , and PCE of $0.15 \% .{ }^{17}$ Interestingly, all the devices incorporating F8BT show significant performance improvements due to the increase of $\mathrm{V}_{\text {oc }}$ and $\mathrm{J}_{\mathrm{sc}}$. It is known that $\mathrm{V}_{\mathrm{oc}}$ is strictly related to the HOMO and LUMO levels of the donor and the acceptor respectively, but this dependence becomes more complex in a three-component system, in which two materials can act as electron donors. ${ }^{64,65}$ The mechanism leading to an enhancement of the $V_{\text {oc }}$ in a threecomponent system is still a matter of debate, although some studies point out that the energy level alignment between the HOMO and LUMO of the three materials can induce an increase of this parameter. ${ }^{57,66-68}$
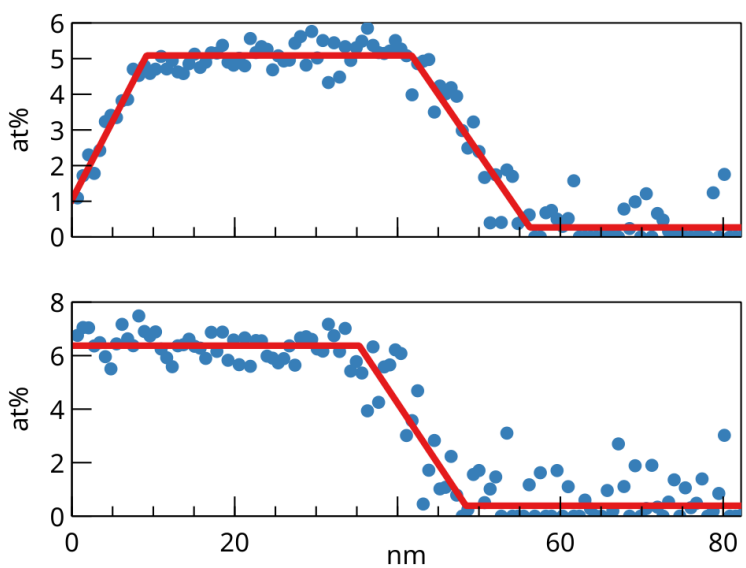

Fig. 7 XPS depth profiles (S2p region) of a F8BT/P3HT junction (upper) and a P3HT layer without F8BT (lower) both over ITO on PET. Once the signal get the zero value the ITO surface has been reached.
Table 1 Photovoltaic parameters of OSCs with different active layers in a PET/ITO/PEDOT:PSS/active-layer/Al architecture.

\begin{tabular}{l|cccc} 
Active Layer & $V_{o c}(\mathrm{~V})$ & $J_{s c}\left(\mathrm{~mA} / \mathrm{cm}^{2}\right)$ & $F F$ & $\% \eta$ \\
\hline P3HT/PCBM $\left(\mathrm{PHJ}_{\text {rif }}\right)$ & 0.48 & 0.82 & 0.38 & 0.15 \\
tc-PHJ $_{2}$-like structure & 0.60 & 2.21 & 0.38 & 0.50 \\
P3HT:F8BT/PCBM $_{\text {P3HT:F8BT/PCBM }}$ thinner & 0.57 & 1.99 & 0.30 & 0.35 \\
& 0.60 & 0.61 & 0.36 & 0.13
\end{tabular}

In our case, a possible explanation for the enhancement of $V_{o c}$ values observed in all devices with F8BT, involves the presence of higher LUMO energy level of F8BT compared to that of PCBM. Regarding the $\mathrm{J}_{\mathrm{sc}}$, the above fluorescence measurements suggest that the improvements are due not only to the extended absorption but also to the cascade energy structure, which would energetically favor CT at the interfaces.

However, comparing the photovoltaic parameters of the two devices with F8BT, one can note that the tc- $\mathrm{PHJ}_{2}$-like architecture unexpectedly ensures better performance than P3HT:F8BT/PCBM, both in terms of $\mathrm{J}_{\mathrm{sc}}, \mathrm{V}_{\mathrm{oc}}$, and FF. The highest Jsc value obtained for the tc- $\mathrm{PHJ}_{2}$, almost three times higher than that of the reference device, agrees with the above picture that a cascade energy effect with F8BT located in between the donor and acceptor systems is dominant compared to the ET process. Indeed, the more efficient ET in P3HT:F8BT/PCBM device (Figure 6), due to the larger P3HT:F8BT interface, does not result in a better performance. From the point of the view of the transfer processes at the interfaces, the P3HT:F8BT/PCBM architecture could be regarded as a combination of two different architectures: the tc- $\mathrm{PHJ}_{1}$ with F8BT on the bottom, in contact only with the P3HT, and the tc$\mathrm{PHJ}_{2}$ with F8BT at the P3HT/PCBM interface.

In other words, all transfer processes that occur at the different interfaces contribute to the final photogenerated current, but not all the interfaces are equally efficient in terms of exciton dissociation and thus of CT. As mentioned above, it is known that the charge separation is not efficient at the F8BT/PCBM interfaces. Furthermore, here we showed that when the F8BT is in contact only with $\mathrm{P} 3 \mathrm{HT}$ in the tc- $\mathrm{PHJ}_{1}$ configuration, no CT improvement is recorded. In this regard, the results are in good agreement with the fluorescence measurements revealing that the F8BT needs to be located in between the donor and acceptor systems for an efficient CT.

As to the low FF in the P3HT:F8BT/PCBM device, it can be likely ascribed to an increased recombination of charge carriers due to the P3HT:F8BT mixed system, which does not show the net spatial separation of positive and negative charges as in a $\mathrm{PHJ}$. Accordingly, also the $\mathrm{V}_{\text {oc }}$ value decreases compared to that of the tc- $\mathrm{PHJ}_{2}$-like structure, although it remains higher than that of the device without F8BT, as discussed previously. In this regard, it is important to point out that in $\mathrm{BHJ}$ devices, the large donor-acceptor interface promoting the exciton dissociation inhibits the geminate recombination. However, the FF and the Voc values are not primarily determined by electric-fielddependent charge separation but rather by nongeminate recombination losses. ${ }^{69-71}$ For this reason, $\mathrm{PHJ}$ devices usually show FF and $\mathrm{V}_{\text {oc }}$ values higher than those of BHJs. 
The photovoltaic parameters reported in Table 1 refer to the best devices where the F8BT amount has been optimized in terms of P3HT:F8BT ratio or F8BT thickness (see ESI). In this regard and in agreement with literature, we found a significant dependence of $V_{\text {oc }}$ on the composition of the acceptors. $57,72-74$ Indeed, the $\mathrm{V}_{\mathrm{oc}}$ values increases from $0.48 \mathrm{~V}$ to $0.74 \mathrm{~V}$ depending on the F8BT to PCBM ratio.

Finally, in light of the interesting fluorescence results described above, we fabricated a photovoltaic device whit an active P3HT:F8BT/PCBM layer thick around $15 \mathrm{~nm}$. The photovoltaic parameters of this device are shown in Table 1. In this case, the higher $\mathrm{FF}$ and $\mathrm{V}_{\text {oc }}$ values compared to the analogous device but with a higher thickness of the active layer, could be due to the reduction of the effects of non-geminal recombination in the thin heterojunction layer. These results, combined with a $J_{s c}$ that, despite the strong reduction of the thickness, decreased from 0.82 to $0.61 \mathrm{mAcm}^{-2}$ only and led to a comparable PCE value to that obtained in the thicker reference device. Therefore, no significant reduction of the photovoltaic performances has been detected after the thinning of the device, most likely due to the improved $\eta_{\text {diss }}$ and $\eta_{\text {ass }}$ resulting from the addition of the F8BT. The thinner device showed an increased transmittance between $350 \mathrm{~nm}$ and $650 \mathrm{~nm}$, from $5 \%$ to $65 \%$ at the point of the maximum absorption of the heterojunction (Figure 8).

\section{Conclusions}

Once both CT and ET processes occur in a three-component photovoltaic solar cell, the third component needs to be located in an appropriate position to obtain an efficient CT induced by a cascade level effect. In the case of a planar solar cell made of $\mathrm{P} 3 \mathrm{HT}, \mathrm{PCBM}$ and F8BT, this last system allows for such an effect by placing in between the donor P3HT and the acceptor PCBM. The ET process can be improved by mixing $\mathrm{P} 3 \mathrm{HT}$ and $\mathrm{F} 8 \mathrm{BT}$ in an active P3HT:F8BT/PCBM layer. This may be very useful in transparent solar cells since it allows for a decreased thickness of the active layer.

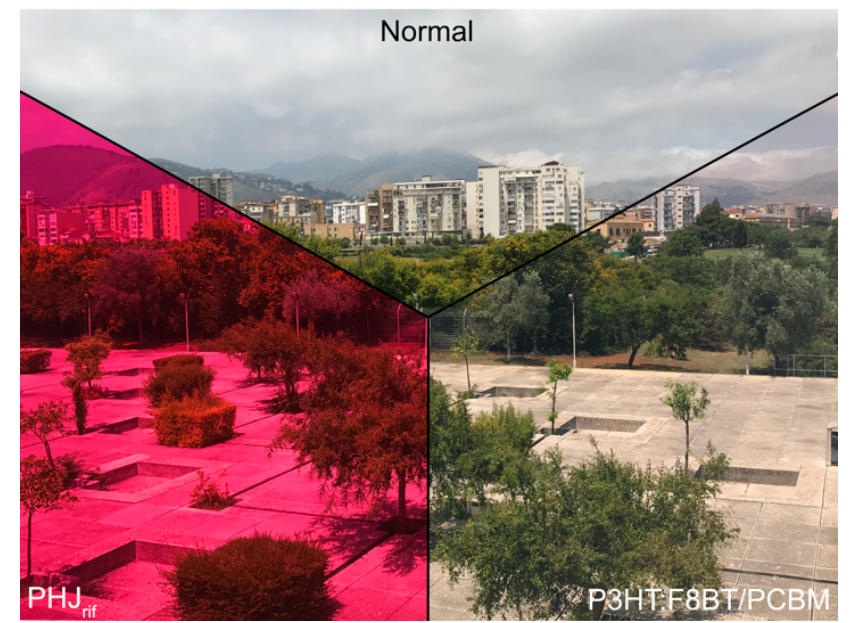

Fig. 8 Comparison between a normal photograph and those taken through the thin films of $\mathrm{PHJ}_{\text {rif }}$ and $\mathrm{P} 3 \mathrm{HT}: \mathrm{F} 8 \mathrm{BT} / \mathrm{PCBM}$. The photographs were taken with the same white balance.
However, the P3HT:F8BT blend limits the P3HT-PCBM CT with respect to a planar $\mathrm{P} 3 \mathrm{HT} / \mathrm{F} 8 \mathrm{BT} / \mathrm{PCBM}$ cascade level configuration and a compromise between $\mathrm{CT}$ and $\mathrm{ET}$ has to be found to get higher PCE or transparency.

By the above approach, in this paper we developed threecomponent highly transparent heterojunctions showing in flexible OCS devices PCE comparable to those observed by the colorful reference P3HT/PCBM PHJ OSCs on PET/ITO substrates.

\section{Conflicts of interest}

There are no conflicts to declare

\section{Acknowledgements}

Italian MiUR is acknowledged for funding through the program PON R\&C 2007-2013 (PONO3PE_00214_1 - TECLA). Aten Center (University of Palermo; project "Mediterranean Center for Human Health Advanced Biotechnologies (CHAB)" PON R\&C 2007-2013) is acknowledged for hospitality and service.

Notes and references

¥ Footnotes relating to the main text should appear here. These might include comments relevant to but not central to the matter under discussion, limited experimental and spectral data, and crystallographic data.

$\S$

$\S \S$

etc.

1. L. Hui, X. Zuo, D. Liming and W. Jizheng, Science Bulletin, 2018, 63, 340.

2. L. Meng, Y. Zhang, X. Wan, C. Li, X. Zhang, Y. Wang, X. Ke, Z. Xiao, L. Ding, R. Xia, H.-L. Yip, Y. Cao and Y. Chen, Science, 2018.

3. J. Song, C. Li, L. Zhu, J. Guo, J. Xu, X. Zhang, K. Weng, K. Zhang, J. Min, X. Hao, Y. Zhang, F. Liu and Y. Sun, Adv Mater, 2019, 31, e1905645.

4. Y. Li, G. Xu, C. Cui and Y. Li, Adv. Energy Mater., 2018, 8.

5. G. Giuliano, S. Cataldo, M. Scopelliti, F. Principato, D. Chillura Martino, T. Fiore and B. Pignataro, Advanced Materials Technologies, 2019, DOI: 10.1002/admt.201800688, 1800688.

6. L. Jagadamma, M. Senani, A. Labban, I. Gereige, N. Ndjawa, O. Guy, J. C. D. Faria, T. Kim, K. Zhao and F. Cruciani, Adv. Energy Mater., 2015, 5.

7. M. Al-Ibrahim, H. K. Roth, U. Zhokhavets, G. Gobsch and S. Sensfuss, Solar Energy Materials and Solar Cells, 2005, 85, 13-20.

8. A. Iwan, I. Tazbir, M. Sibiński, B. Boharewicz, G. Pasciak and E. Schab-Balcerzak, Mater. Sci. Semicond. Process., 2014, 24, 110-116.

9. Y.-T. Cheng, J.-J. Ho, C.-K. Wang, W. Lee, C.-C. Lu, B.-S. Yau, J.-L. Nain, S.-H. Chang, C.-C. Chang and K. L. Wang, Appl. Surf. Sci., 2010, 256, 7606-7611. 
10.

Y.-W. Syu, P.-Y. Huang, H.-D. Li, C.-L. Hsu, K.-C. Chiu, C. Kim, M.-C. Chen and Y.-C. Chao, J. Phys. Chem. C, 2014, 118, 9958-9965.

11. D. Chen, F. Liu, C. Wang, A. Nakahara and T. P. Russell, Nano Letters, 2011, 11, 2071-2078.

12. D. Heinemann Marc, K. Ananthanarayanan, L. N. S. A. Thummalakunta, H. Yong Chian and J. Luther, Journal, 2011, 1, 291.

13. K. H. Lee, P. E. Schwenn, A. R. G. Smith, H. Cavaye, P. E. Shaw, M. James, K. B. Krueger, I. R. Gentle, P. Meredith and P. L. Burn, Adv. Mater., 2011, 23, 766-770.

$14 . \quad J$. S. Moon, C. J. Takacs, Y. Sun and A. J. Heeger, Nano Letters, 2011, 11, 1036-1039.

15. M. Casalegno, D. Kotowski, A. Bernardi, S. Luzzati, R. Po and G. Raos, Phys. Chem. Chem. Phys., 2015, 17, 2447-2456.

16. J. Lee, Y. K. Jung, D. Y. Lee, J.-W. Jang, S. Cho, S. Son, J. Jeong and S. H. Park, Synth. Met., 2015, 199, 408-412.

17. C. Sartorio, S. Scaramuzza, S. Cataldo, V. Vetri, M. Scopelliti, M. Leone, V. Amendola and B. Pignataro, J. Phys. Chem. C, 2016, 120, 26588-26599.

18. D. Chi, S. Qu, Z. Wang and J. Wang, J. Mater. Chem. C, 2014, 2, 4383.

19. M. S. Ryu, H. J. Cha and J. Jang, Current Applied Physics, 2010, 10, S206-S209.

20. W. L. Ma, C. Y. Yang, X. Gong, K. Lee and A. J. Heeger, Advanced Functional Materials, 2005, 15, 1617-1622.

21. A. J. Moulé and K. Meerholz, Adv. Mater., 2008, 20, 240245.

22. P. Kovacik, G. Sforazzini, A. G. Cook, S. M. Willis, P. S. Grant, H. E. Assender and A. A. R. Watt, ACS Applied Materials \& Interfaces, 2011, 3, 11-15.

23. A. Tada, Y. Geng, Q. Wei, K. Hashimoto and K. Tajima, Nat. Mater., 2011, 10, 450-455.

24. S. A. Hawks, J. C. Aguirre, L. T. Schelhas, R. J. Thompson, R. C. Huber, A. S. Ferreira, G. Zhang, A. A. Herzing, S. H. Tolbert and B. J. Schwartz, J. Phys. Chem. C, 2014, 118, 17413-17425.

$25 . \quad$ B. Kitchen, O. Awartani, R. J. Kline, T. McAfee, H. Ade and B. T. O'Connor, ACS Applied Materials \& Interfaces, 2015, 7, $13208-13216$.

26. V. S. Gevaerts, L. J. A. Koster, M. M. Wienk and R. A. J. Janssen, ACS Applied Materials \& Interfaces, 2011, 3, 32523255.

27. A. L. Ayzner, C. J. Tassone, S. H. Tolbert and B. J. Schwartz, J. Phys. Chem. C, 2009, 113, 20050-20060.

28. G. Dennler, M. C. Scharber and C. J. Brabec, Adv. Mater., 2009, 21, 1323-1338.

29. S.-I. Na, S.-S. Kim, J. Jo, S.-H. Oh, J. Kim and D.-Y. Kim, Advanced Functional Materials, 2008, 18, 3956-3963.

30. B. P. Rand, P. Peumans and S. R. Forrest, J. Appl. Phys., 2004, 96, 7519-7519.

31. J. You, L. Dou, Z. Hong, G. Li and Y. Yang, Progress in Polymer Science, 2013, 38, 1909-1928.

32. M. Riede, C. Uhrich, J. Widmer, R. Timmreck, D. Wynands, G. Schwartz, W.-M. Gnehr, D. Hildebrandt, A. Weiss, J. Hwang, S. Sundarraj, P. Erk, M. Pfeiffer and K. Leo, Advanced Functional Materials, 2011, 21, 3019-3028.

33. S. Lu, X. Guan, X. Li, J. Liu, F. Huang and W. C. H. Choy, Nano Energy, 2016, 21, 123-132.

34. M. R. Khan, B. Ray and M. A. Alam, Solar Energy Materials and Solar Cells, 2013, DOI: 10.1016/j.solmat.2013.08.008.
35.

H. Kang, G. Kim, J. Kim, S. Kwon, H. Kim and K. Lee, Adv Mater, 2016, 28, 7821-7861.

H.-T. Ge, S. Yuan, Z.-Z. Li, Q.-W. Liu and L.-S. Liao, Org. Electron., 2019, 75, 105423.

M. M. Tavakoli, R. Po, G. Bianchi, A. Cominetti, C. Carbonera, N. Camaioni, F. Tinti and J. Kong, Proc. Natl. Acad. Sci. U. S. A., 2019, 116, 22037-22043.

S. Honda, T. Nogami, H. Ohkita, H. Benten and S. Ito, ACS Applied Materials \& Interfaces, 2009, 1, 804-810.

J.-S. Huang, T. Goh, X. Li, M. Y. Sfeir, E. A. Bielinski, S. Tomasulo, M. L. Lee, N. Hazari and A. D. Taylor, Nat Photon, 2013, 7, 479-485.

M. Raissi, H. Erothu, E. Ibarboure, H. Cramail, L. Vignau, E. Cloutet and R. C. Hiorns, J. Mater. Chem. A, 2015, 3, 1820718221.

C. Sartorio, V. Campisciano, C. Chiappara, S. Cataldo, M. Scopelliti, M. Gruttadauria, F. Giacalone and B. Pignataro, J. Mater. Chem. A, 2018, DOI: 10.1039/C7TA09387J.

Y. Kim, S. Cook, S. A. Choulis, J. Nelson, J. R. Durrant and D. D. C. Bradley, Synth. Met., 2005, 152, 105-108.

L. Lu, T. Xu, W. Chen, E. S. Landry and L. Yu, Nat Photon, 2014, 8, 716-722.

K. Nakano and K. Tajima, Adv Mater, 2017, 29.

C. W. Schlenker, V. S. Barlier, S. W. Chin, M. T. Whited, R. E. McAnally, S. R. Forrest and M. E. Thompson, Chem. Mater., 2011, 23, 4132-4140.

M. Sim, J. S. Kim, C. Shim and K. Cho, Chem. Phys. Lett., 2013, 557, 88-91.

P. Cheng, M. Zhang, T. K. Lau, Y. Wu, B. Jia, J. Wang, C. Yan, M. Qin, X. Lu and X. Zhan, Adv Mater, 2017, 29, 1605216.

P. Cheng, J. Wang, Q. Zhang, W. Huang, J. Zu, R. Wang, S-Y Chang, P. Sun, L. Meng, H. Zhao. H-W Cheng, Y. Huang T. Y. Liu, C. Wang, C. Zhu, W. You, Y. Yang X. Zhan, Adv Mater, 2018, 30, 1801501.

M. A. Digman, V. R. Caiolfa, M. Zamai and E. Gratton, Biophys. J., 2008, 94, L14-L16.

C. Stringari, A. Cinquin, O. Cinquin, M. A. Digman, P. J. Donovan and E. Gratton, Proceedings of the National Academy of Sciences, 2011, 108, 13582-13587.

S. D. Stranks, C. Weisspfennig, P. Parkinson, M. B. Johnston, L. M. Herz and R. J. Nicholas, Nano Letters, 2011, 11, 66-72. J. U. Lee, Y. D. Kim, J. W. Jo, J. P. Kim and W. H. Jo, J. Mater. Chem., 2011, 21, 17209-17218.

S. Cataldo, C. Sartorio, F. Giannazzo, A. Scandurra and B. Pignataro, Nanoscale, 2014, 6, 3566-3575.

O. Hideo, K. Junya, G. Jiamo, B. Hiroaki and I. Shinzaburo,

PHOTOE, 2011, 1, 11118.

Phys. D: Appl. Phys., 2009, 42, 055105.

S. V. Chasteen, S. A. Carter and G. Rumbles, 5938, 59380J59380J-59311, 2005.

L. Lu, M. A. Kelly, W. You and L. Yu, Nat. Photonics, 2015, 9, 491-500.

P. Cheng, Y. Li and X. Zhan, Energy \& Environmental Science, 2014, 7, 2005-2011.

H. Cha, D. S. Chung, S. Y. Bae, M. J. Lee, T. K. An, J. Hwang, K. H. Kim, Y. H. Kim, D. H. Choi and C. E. Park, Advanced Functional Materials, 2013, 23, 1556-1565.

G. Arrabito, F. Cavaleri, A. Porchetta, F. Ricci, V. Vetri, M. Leone and B. Pignataro, Advanced Biosystems, 2019, 3, 1970074. 
61. E. Rao, V. Foderà, M. Leone and V. Vetri, Biochimica et Biophysica Acta (BBA) - General Subjects, 2019, 1863, 784794.

62. J. Piris, T. E. Dykstra, A. A. Bakulin, P. H. M. v. Loosdrecht, W. Knulst, M. T. Trinh, J. M. Schins and L. D. A. Siebbeles, J. Phys. Chem. C, 2009, 113, 14500-14506.

63. Y. Xie, Y. Li, L. Xiao, Q. Qiao, R. Dhakal, Z. Zhang, Q. Gong, D. Galipeau and X. Yan, J. Phys. Chem. C, 2010, 114, 1459014600.

64. M. C. Scharber, D. Muhlbacher, M. Koppe, P. Denk, C. Waldauf, A. J. Heeger and C. J. Brabec, Adv. Mater., 2006, 18, 789.

65. A. Gadisa, M. Svensson, M. R. Andersson and O. Inganas, Appl. Phys. Lett., 2004, 84, 1609-1611.

66. Q. An, F. Zhang, L. Li, J. Wang, Q. Sun, J. Zhang, W. Tang and Z. Deng, ACS Applied Materials \& Interfaces, 2015, 7, 36913698.

67. J.-K. Chang, Y.-C. Kuo, Y.-J. Chen, A.-L. Lo, I. H. Liu, W.-H. Tseng, K.-H. Wu, M.-H. Chen and C.-I. Wu, Org. Electron., 2014, 15, 3458-3464.

$68 . \quad$ J.-H. Huang, M. Velusamy, K.-C. Ho, J.-T. Lin and C.-W. Chu, J. Mater. Chem., 2010, 20, 2820-2825.

69. D. Credgington, Y. Kim, J. Labram, T. D. Anthopoulos and J. R. Durrant, J. Phys. Chem. Lett., 2011, 2, 2759-2763.

70. C. Göhler, A. Wagenpfahl and C. Deibel, Advanced Electronic Materials, 2018, DOI: 10.1002/aelm.201700505.

71. D. Credgington, R. Hamilton, P. Atienzar, J. Nelson and J. R. Durrant, Advanced Functional Materials, 2011, 21, 27442753.

72. L. Yang, H. Zhou, S. C. Price and W. You, J. Am. Chem. Soc., 2012, 134, 5432-5435.

73. R. A. Street, D. Davies, P. P. Khlyabich, B. Burkhart and B. C. Thompson, J. Am. Chem. Soc., 2013, 135, 986-989.

74. P. P. Khlyabich, B. Burkhart and B. C. Thompson, J. Am. Chem. Soc., 2011, 133, 14534-14537. 